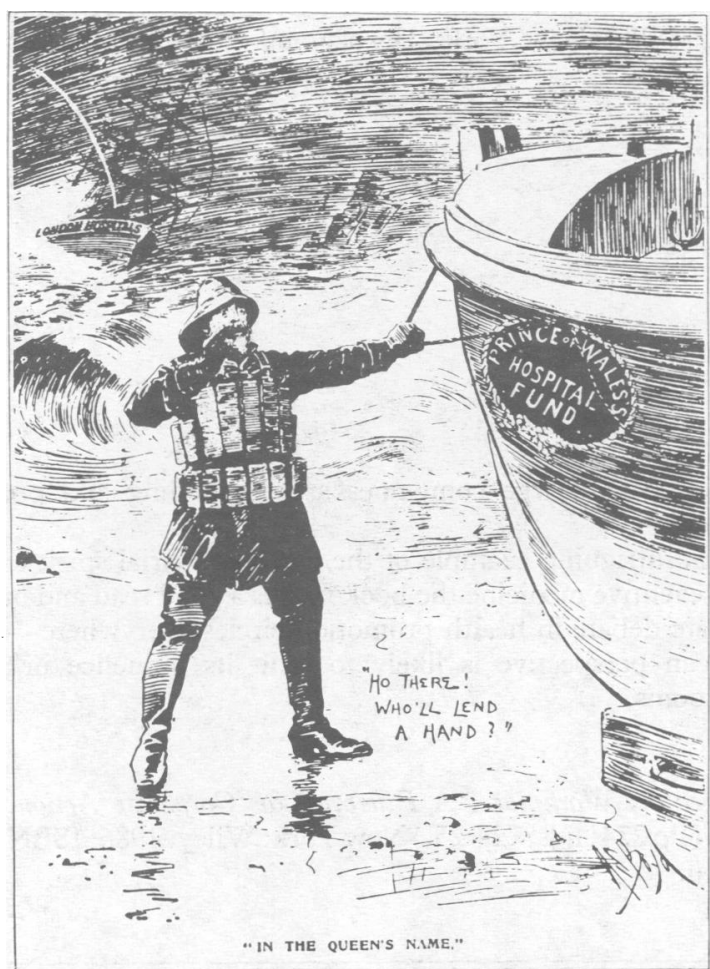

Appeal for the Prince of Wales's Hospital Fund.

the second half of the nineteenth century they were being purpose built by the best architects, sometimes on a grand scale-the Whittington and Whipps Cross Hospital for example - to treat the local sick. An inquiry in 1865 had shown that they were already treating more patients than the voluntary hospitals and had a wealth of clinical material which, it was suggested, ought to be made available for teaching. They had become, said the Lancet, "the great state hospitals of the metropolis."

\section{The centre ought to hold}

Medical schools had grown up in association with the voluntary hospitals and did not become part of the University of London till 1900. Repeated attempts throughout the period to amalgamate the smaller schools came to nothing; instead the early years saw the separation of the "United Hospitals" of St Thomas's and Guy's and of University College students from the Middlesex Hospital. Over 100 years later the wheel has turned ironically full circle.

Far sighted individuals realised that the cost and complexity of medicine could only be met by rationalisation and some form of central control; even so some people believed in 1888 that "England would have taken a long step backwards if the hospitals of London were ever to be supported by the state. It would be hard to conceive of a greater disaster." The pacè of change accelerated with the need for planning for both world wars, and the troubled birth and even more painful growth of the National Health Service is documented in the last quarter of the book.

"History to be interesting and valuable should be recorded by persons of talent and prejudice ..." wrote Charles Macomb Flandrau. Dr Rivett's research and scholarship sit so lightly on the narrative that one has the distinct impression that he was present at the time, observing and noting down the interminable debate. Anyone involved in the present London medical scene will not only enjoy reading his account, but may well wonder whether we will be any further forward in another 150 years.

King's Fund Historical Series. No 4. "The Development of the London Hospital System 1823-1982.” G Rivett. (Pp 424; figs; £30.) Oxford: Oxford University Press, 1986, for The King Edward's Hospital Fund for London. ISBN 0-19-724633-8.

\title{
Found wanting
}

\section{ROBIN HULL}

A fascinating book that aims at alerting the thinking mass of American people to the dire state of medical care in their country, America's Health in the Balance is not just about the United States for the problems it describes are as apparent, if in different proportion, in many other countries such as Britain and the Netherlands where costs soar and care is patchily and inequitably delivered by an ever increasing number of providers.

Dr Hiatt, professor of medicine and dean for 12 years of the Harvard School of Public Health, describes the problem of delivery of care in the USA where as many as 37 million people are medically uninsured and many more have difficulty in finding primary care other than in the costly emergency rooms of secondary and tertiary care hospitals. Where costs are met by third parties, and technology has bred expectation in the consumer and the threat of litigation in the provider, there is massive overinvestigation and treatment. To make matters worse there are too many doctors (there will be an estimated excess of 150000 by 1999) and maldistribution between generalism and specialism. These problems have to be seen in the context of shortage of resources made worse by the necessary demands of an aging population and the unnecessary demands of a defence strategy that provides enough nuclear warheads completely to destroy an enemy a thousand times.

Looking abroad, the author seeks lessons in Canada, China, and Britain, arguing the need for delivering sound primary health care to everyone, coordinated by a "gatekeeper" physician and backed by appropriate use of hospital medicine. He stresses neglected aspects of prevention, basic research, and the rational application of technology where altered priorities might save money, life, and the average American's confidence in medicine.

In suggesting a solution Dr Hiatt imagines an American city in 2000 in which a central, singly funded system provides primary care through health maintenance organisations or independent practice arrangements in which doctors look after 1500-1700 patients. Patients could choose their family doctors who in turn would choose specialists, allowing both levels of care to be paid by capitation, and built in quality control would include help for sick physicians. He answers criticism that this plan concentrates too much power in a regional health corporation and that capitation payment implies neglect, but does not realise that removal of the referring doctor's choice of specialist for his patient's problem destroys an important role of the gatekeeper. Adoption of the author's concepts must depend on alteration of both medical and lay opinion, and the argument might be strengthened by greater stress on ethical and educational issues.

The author worries that his book may be out of date by the time it is published. He need not fear; many who have watched American medicine from Europe these past two decades have urged similar reforms as, with increasing alarm, we have watched the same sort of 
problems develop here. I suspect that he may still have to wait some time before the message is heard but meanwhile all who care about medicine should read his book.
America's Health in the Balance. Choice or Chance? H H Hiatt. (Pp 272; \$18.95.) New York: Harper and Row, 1987. ISBN 0-06039063-8.

\title{
Business is blooming
}

\author{
PETER J BAXTER
}

Worksite health promotion adds up to good business-that is the transatlantic message of this book. Good health is also good for business. It is good for the American insurance companies, which make higher profits when there are fewer sickness claims, and good for the companies that endorse health promotion: sickness absence and employee turnover are reduced, productivity is increased, and health insurance premiums should cost less. The author, who is the head of a major insurance company in the United States, perceived a few years ago that American industry and the insurance companies shared a common goal-to contain escalating medical costs-and that the way they could unite was through health promotion in the workplace. Employees would also gain by becoming healthier and living longer.

This actuary's dream became reality with the formation of the first wellness council in Omaha, Nebraska, in 1982, the forerunner of at least 10 more in other cities. The book is a crusading, personal, and rather uncritical account of worksite health promotion and is endorsed by several chairmen of multinational companies and aimed at business leaders. Its main value for health professionals lies in its description of the structure and operation of wellness councils, one of several recent innovations in workplace health promotion in the United States, but it is also of considerable interest as one of the first books written about the workplace and the health promotion movement.

Health promotion is more than just health education as it seeks to create the conditions in which healthy ways of living can develop; the workplace can be an important arena for its growth if only managements can be persuaded to give it their support. For a fairly small outlay firms could make a start by introducing company policies on smoking and alcohol, improving nutrition, and encouraging exercise. By subscribing to the local wellness council a company, irrespective of its size, would receive a consultative service, technical help, and advice on organisations-profit and non-profit making - that could provide the necessary services. Such organisations, together with government groups, schools, and universities, can all belong to the wellness council. Local health professionals can participate too: the medical advisory committee keeps an eye on the scientific soundness of the services and advice provided. Employees' families are not excluded: the wellness message is intended to reach beyond the workplace and into homes. The wellness council, itself a non-profit making organisation under the direction of prominent local business leaders, becomes the catalyst for workplace and societal change towards healthier living.

But does it work and can it happen here? The author admits that the evidence from company accounts is mainly anecdotal and not yet complete. In Britain businesses do not directly pay out a major share of total health costs as they do in the United States, and so the major factor in the development of wellness councils as described is missing here, but the private medical insurance companies could provide a stimulus if they offered lower subscriptions to companies adopting health promotion and health screening. Should not district health promotion teams be doing more to foster business support groups, particularly for smaller firms, perhaps even in a way analogous to the wellness councils, or are they destined to follow trends rather than to lead? The movement towards health promotion is undoubtedly growing apace among employees, whether in the spread of gymnasiums for City money makers or in the popularity of lunchtime relaxation classes for office and shop floor workers. Many large companies are responding and providing facilities.

As an intriguing example of the entrepreneurial spirit entering into preventive medicine the book makes a good read and ought to stimulate debate in health promotion circles everywhere-but its American perspective is likely to limit its influence in British boardrooms.

The Healthy Workplace: A Blueprint for Corporate Action. W M Kizer. (Pp 224; figs; £24·25.) New York: Wiley, 1986. ISBN 0-47184531-0.

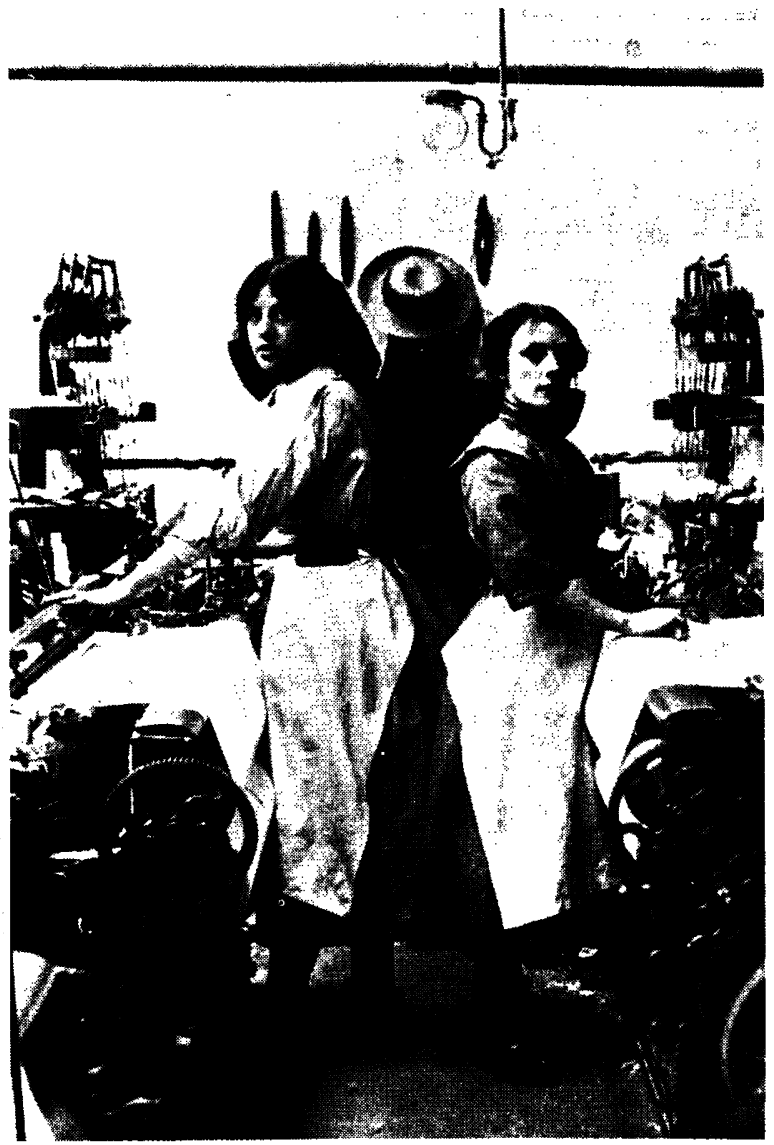

Manchester mill girls pictured in Day In Day Out (£1·25. Gatehouse Project, St Luke's, Sawley Road, Miles Platting, Manchester M10 8DB. ISBN 0-906253-19-5). A selection of taped reminiscences by women in wards 14 and 10 at Monsall Hospital, North Manchester, the book gives a vivid picture of life 40,50 , and more years ago, as well as reflecting the therapeutic value of getting elderly people to explore their memories. 